\title{
UPDATED PERIODONTAL GUIDELINES FOR UNDER 18s
}

The importance of periodontal screening of young people is being reinforced jointly by the British Society of Paediatric Dentistry (BSPD) and the British Society of Periodontology and Implant Dentistry (BSP) as updated national guidelines for the management of patients aged under 18 in the primary care setting are launched.

The updated guidelines, just published on the websites of both BSP and BSPD, incorporate the new Classification System devised at the 2017 World Workshop. ${ }^{1}$ The 2021 guidelines also reflect the new method of staging and grading periodontitis arising from the same landmark meeting, which influences the management of all patients.

At the heart of any screening is the BPE (Basic Periodontal Examination) first developed in 1986. It wasn't until 2012, however, that BPE screening was produced for the management of young people from the age of seven. A simplified version, the sBPE, examines only six teeth: the permanent molars and one incisor in the upper arch and one incisor in the lower arch; these reflect teeth susceptible to periodontal disease in this age group.

The two clinicians who developed both the 2012 guidelines and the updated version in 2021 on behalf of BSP and BSPD respectively are: Professor Valerie Clerehugh, Emeritus Professor of Periodontology,

Department of Restorative Dentistry, School of Dentistry, University of Leeds, and Dr Susan Kindelan, Consultant in Paediatric Dentistry, Leeds Dental Institute, Leeds Teaching Hospitals Trust.

Professor Clerehugh and Dr Susan Kindelan agree: 'Gingival diseases are prevalent in young people, and reversible gingival inflammation can progress to the initial stages of irreversible periodontal destruction in adolescents. While severe forms of periodontal diseases are uncommon in the younger age groups, identification of those affected by gingival and periodontal problems is important and dental practitioners have an important role to play in their early recognition and diagnosis.

'Practitioners should be aware that smoking in children and young people, including the use of e-cigarettes, and higher levels of obesity are factors which might have an impact on the prevalence of gingivitis and periodontitis.'

Dr Susan Kindelan said: 'Prevention of periodontal diseases is hugely important. Patients treated by BSPD members are more likely to have co-morbidities or complex syndromes which impact on gum conditions. For this cohort of patients, early diagnosis and referral is recommended.

BSPD spokesperson Claire Stevens said: 'So much has changed in the field of periodontology over recent years, this update is timely. We very much hope to build awareness of the important of the SBPE so that it is integral to all appointments with young people aged seven and over'.

\section{Reference}

1. American Academy of Periodontology. Proceedings from the 2017 World Workshop on the Classification of Periodontal and Peri-Implant Diseases and conditions. 2017. Available at: https://www.perio.org/2017wwdc (accessed October 2021).

\section{DENTAL PRACTICE REDECORATES WITH MUSIC PAINTINGS FOR PATIENT WELLBEING}

As of this October, clients at the Llanishen Dental Centre in Cardiff will be treated to a visual feast while they wait for treatment. The walls are now filled with music paintings. These are one square metre of abstract explosions of shape, pattern and colour, created to distract and make people feel good.

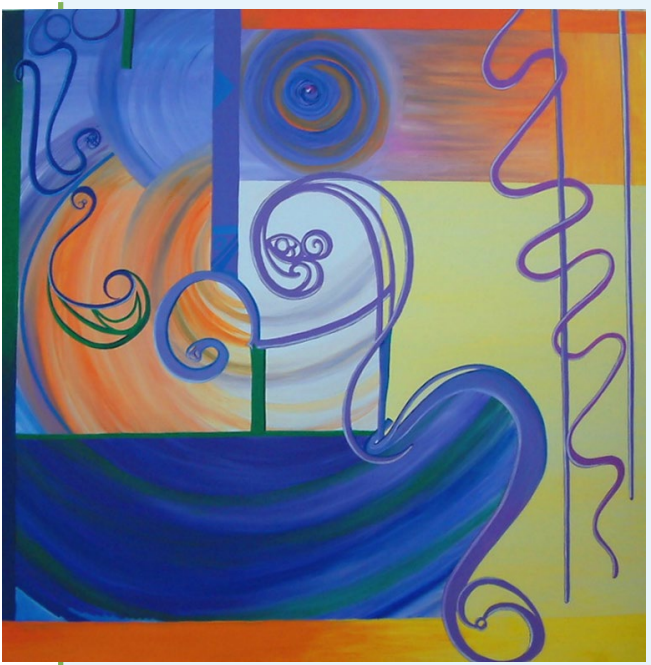

Practice owners Rhys Loxton and David Morgan, knowing that there is increasing scientific evidence of art having measurable positive effects on health, invited local artist Shaun Ray, a champion of art, health and wellbeing, to put on a rolling exhibition of his work and make the experience of visiting the dentist refreshingly new.

Dr Loxton said: 'I want our clients to always have the very best and as we come out of COVID restrictions, these paintings really brighten up the environment; they're wonderful'.

Artist Shaun Ray has, until recently, run workshops for older members of the community, but COVID lockdown stopped all that and sent him back into his studio, where he, like so many artists, has been afforded the luxury of time to create.

Shaun said: 'I'm so happy that my work can be seen in a health setting. Art should be seen more in real places, not just in galleries and museums'.

Staff at the dental centre have also

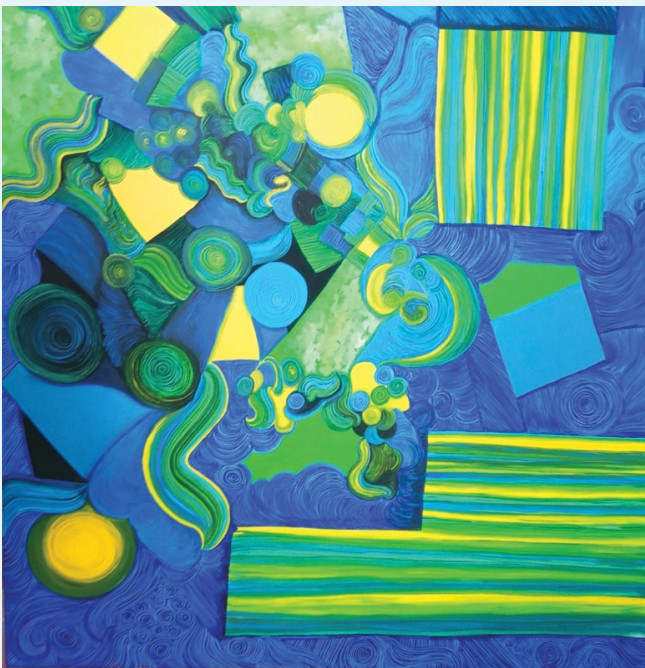

Examples of Shaun Ray's music paintings

benefitted from the colourful new art work. A dental technician commented: 'On the first day it was a pleasure to be able to have a different conversation with clients. People really like [the art work] and it's great that a local artist gets a chance to show off his work'.

www.shaunray.wixsite.com/ musicpainting 